\title{
Pfeiffer syndrome type 1
}

INSERM

\section{Source}

INSERM. (1999). Orphanet: an online rare disease and orphan drug data base. Pfeiffer syndrome type 1. ORPHA:93258

Pfeiffer syndrome type 1 (PS1) is a mild to moderately severe type of Pfeiffer syndrome (PS; see this term), characterized by bicoronal craniosynostosis, variable finger and toe malformations, and in most cases, normal intellectual development. 